\title{
The Electrokinetic Behavior of Red Blood Cells from a Patient with Tn Syndrome by Doppler Electrophoretic Light Scattering Analysis
}

\author{
Toshinori Omi, Eiji KaJil and Shigenori Ikemoto \\ Department of Legal Medicine and Human Genetics, Jichi \\ Medical School, Tochigi 329-04
}

\begin{abstract}
Oмг, T., KaJII, E. and Iкемото, S. The Electrokinetic Behavior of Red Blood Cells from a Patient with Tn Syndrome by Doppler Electrophoretic Light Scattering Analysis. Tohoku J. Exp. Med., 1994, 174 (4), 369-377— The Tn syndrome is an acquired form of persistent mixed-field polyagglutination displaying two distinct populations of $\mathrm{Tn}$ positive (Tn) and Tn negative (tn) red blood cells (RBCs). We investigated the electrophoretic behavior of RBCs showing polyagglutination from a patient with Tn syndrome by the doppler electrophoretic light scattering (D.E.L.S.) analysis. The mean of zeta potential of normal RBCs from ten individuals was $-13.07 \pm 0.61 \mathrm{mV}$ (mean \pm s.D.). The content of membraneassociated sialic acid equated with the zeta potential of RBCs. Among the proteases ficin was most effective on the zeta potential of RBCs. The zeta potential of the patient $\mathrm{Tn} R B C s$ and tn RBCs were $-4.73 \mathrm{mV}$ and $-13.32 \mathrm{mV}$, respectively. Tn $\mathrm{RBCs}$ reduced $64.5 \%$ of zeta potential compared with tn $\mathrm{RBCs}$ and formed $48.8 \%$. These results may provide some useful information for classification of Tn syndrome._— red blood cells; Tn polyagglutinability; zeta potential; protease; neuraminidase
\end{abstract}

The Tn syndrome is an acquired clonal disorder first characterized by the polyagglutinability of erythrocytes following exposure of a normally masked determinant, the Tn antigen, on the surface of red blood cells (RBCs) (Bird et al. 1971; Bird 1977). The disorder may be associated with a mild hemolytic anemia, leukemia or myeloproliferative diseases (Bird et al. 1976; Baldwin et al. 1979; Ness et al. 1979; Vainchenker et al. 1985). The Tn activation corresponds to the exposure of $\mathrm{N}$-acetylgal-actosaminyl residue carried by cell surface glycoproteins (Darh et al. 1974), resulting in lack of the enzyme 3- $\beta$-D-galactosyl transferase activity in Tn positive (Tn) cells (Cartron et al. 1978a, b; Cartron and Nurden 1979).

Recently we have reported that a Japanese male patient with Tn syndrome

Received March 23, 1994; revision accepted for publication October 6, 1994.

Address for reprints: Shigenori Ikemoto, VMD, MD, Department of Legal Medicine and Human Genetics, Jichi Medical School, Minamikawachi-machi, Kawachi-gun, Tochigi 32904, Japan. 
associated with myelodysplastic syndrome (MDS) (Oyamada et al. 1991; Kamesaki et al. 1993). Peripheral blood cells in the patient with Tn syndrome typically showed two distinct cell populations, Tn positive (Tn) RBCs and Tn negative (tn) RBCs. This paper described the characterization of surface charge on RBCs with Tn syndrome using the doppler electrophoretic light scattering (D.E.L.S.) analysis.

\section{Materials ANd Methods}

\section{Patient}

A 55-year-old Japanese male was admitted to Tottori Prefectural Central Hospital in May 1990 because of a bleeding tendency. Admission laboratory data were: hematocrit $36.5 \%$, hemoglobin $11.9 \mathrm{~g} / 100 \mathrm{ml}$, erythrocytes $3.91 \times 10^{6} \mathrm{ml}$, reticulocyte count $1.9 \%$, white blood cell $1,400 / \mathrm{ml}$, platelets $18,000 / \mathrm{ml}$. The counts of blasts in peripheral and bone marrow blood were 1.0 and $9.0 \%$, respectively. The number of blasts and morphological abnormalities detected in the myeloid series, erythroblasts, and platelets corresponded with those of refractory anemia with excess of blasts (RAEB) in myelodysplastic syndrome (MDS) of FAB classification (Bennett et al. 1982, 1985). The erythrocytes were agglutinated with monoclonal anti-H, but not with monoclonal anti-A or anti-B antibody. The serum contained anti-A and anti-B antibodies. The ABO-blood group system was typed as group $O$. The patient had received no blood transfusions until this admission. The erythrocytes were polyagglutinable and strongly agglutinated with extracts from Dolicos biflous, Saliva sclarea, Vicia Villosa, and Helix pomatia, but unreactive with hexadimethrine bromide, Arachis hypogaea, and cold human serum. The direct and indirect antiglobulin tests were negative. These data indicated expression of the Tn antigen on the erythrocytes. In addition, flow cytometric analyses revealed the $\mathrm{Tn}$ antigen on platelets, granulocyte, monocytes, and lymphocytes. Accordingly, the patient was diagnosed as having Tn syndrome associated with RAEB.

\section{Cell samples}

Red blood cells from a normal donor and the patient with Tn syndrome were drawn into heparinized syringes. The blood samples were washed three times with saline and then suspended in saline to a count of $1 \times 10^{6} \mathrm{RBCs} / \mu \mathrm{l}$.

\section{Treatment of RBCs with various enzymes}

The RBCs from a normal donor were treated with various enzymes. The procedure of papain treatment was performed following the method of Roelcke (Roelcke 1973). Water-soluble papain (Wako, Osaka) was used at a concentration of $209 \mathrm{PU} / \mathrm{ml}$ in 1/15 M PBS, pH 7.3. Dispase (Godo Shusei, Tokyo) were used at a concentration of $10,000 \mathrm{PU} / \mathrm{ml}$ in $1 / 15 \mathrm{M} \mathrm{PBS}, \mathrm{pH}$ 7.3. Trypsin (Wako) and chymotrypsin (Worthington Biochemical, Freehold, NJ, USA) were used at a 
concentration of $16 \mathrm{PU} / \mathrm{ml}$ and $536 \mathrm{PU} / \mathrm{ml}$ in $0.1 \mathrm{M} \mathrm{PBS}, \mathrm{pH}$ 7.7. The procedures of dispase-, trypsin- and chymotrypsin treatment were described in previous report (Kajii et al. 1986). GammaZyme-F (Gamma Biologicals, Houston, TX, USA) was used as a reagent of stabilized ficin solution. Bromelain (Wako) was used as 800 $\mathrm{PU} / \mathrm{ml}$ in 1/15 M PBS, pH 5.5. The neuraminidase treated RBCs ( $\mathrm{T}$ transformation) was preparated using neuraminidase from Vibrio cholera. (Sigma, St. Louis, $\mathrm{MO}, \mathrm{USA}$ ) at a concentration of $0.4 \mathrm{U} / \mathrm{ml}$ in $1 / 15 \mathrm{M} \mathrm{PBS}, \mathrm{pH} 7.3$. Each one $\mathrm{ml}$ of these protease and neuraminidase solutions was mixed with equal volume of packed RBCs. The mixture was incubated at $37^{\circ} \mathrm{C}$ from $20 \mathrm{~min}$ to $4 \mathrm{hr}$, and washed three or five times with saline.

\section{Measurement of sialic acids released from $R B C s$}

The amount of the sialic acids released from RBCs was measured with a reagent of RBC sialic acid test (Kyokuto, Tokyo), according to Warren's method (Warren et al. 1959).

\section{Doppler electrophoretic light scattering (D.E.L.S.)}

The principle and method of D.E.L.S. have been described previously (Eylar et al. 1962). The electrokinetic behavior of the RBCs was studied using D.E.L.S. analyzer (Coulter Electronics, Hialeah, FL, USA). The RBCs were suspended with $0.9 \%$ saline. One milliliter of the $\mathrm{RBCs}$ suspension $\left(1 \times 10^{6} \mathrm{RBCs} / \mu \mathrm{l}\right)$ was injected into the sample chamber. The electrophoresis for the RBCs was carried out at a constant current of $10 \mathrm{~mA}$ for $36 \mathrm{sec}$, and $0.15 \mathrm{M} \mathrm{NaCl}$ solution ( $\mathrm{pH} 5.0$ ) was used as the medium. The RBCs in sample chamber were maintained at $25^{\circ} \mathrm{C}$. Four angles: $8.6^{\circ}, 17.1^{\circ}, 25.6^{\circ}$, and $34.2^{\circ}$ were used to detect cell electrophoresis.

The calculation of the frequency, electrophoretic mobility and zeta potential of RBCs were performed on a system/55 personal computer (IBM Japan, Tokyo) using DELSA 440 control program.

\section{Results}

Since the zeta potential on RBCs is reduced by removing the sialic acid from the normal RBCs, the applicability of D.E.L.S. techniques to the RBCs were examined by measurement of zeta potential on enzymatically modified RBCs, which were treated with neuraminidase treatment under the various conditions. Evidence of a pronounced change in the electrokinetic behavior was revealed by the titration curves shown in Figs. 1 and 2.

Further, the amount of sialic acid released from the RBCs through neuraminidase treatment was determined. The content of membrane-associated sialic acid equated with the zeta potential of RBCs (Fig. 3). The coefficient of correlation was 0.995 and the equation of linear regression line was $\mathrm{y}=-0.092 \mathrm{X}+13.01$. As well as neuraminidase treatment, the RBCs treated with various proteases showed reduction of zeta potential. The zeta potential of RBCs treated with 


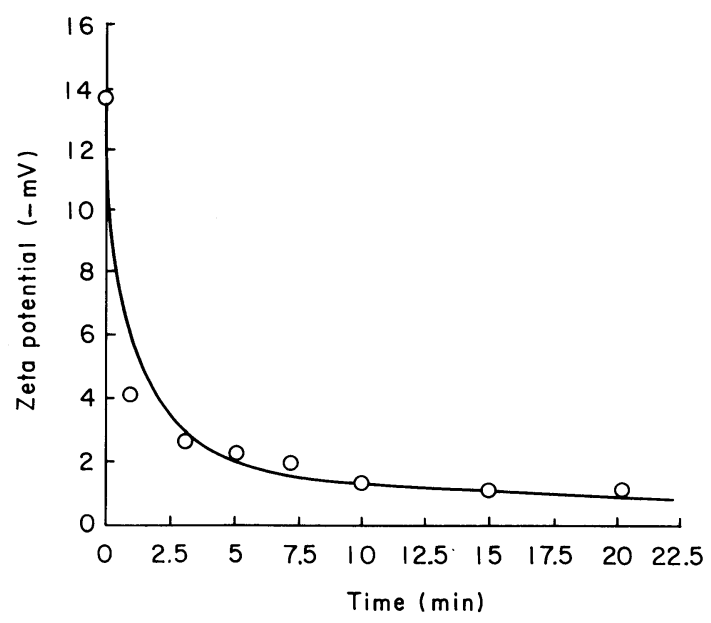

Fig. 1. The relation between the zeta potential value and the treatment time with neuraminidase. The RBCs were incubated with neuraminidase at a concentration of $0.4 \mathrm{U} / \mathrm{ml}$ at $37^{\circ} \mathrm{C}$ for varying period incubation time.

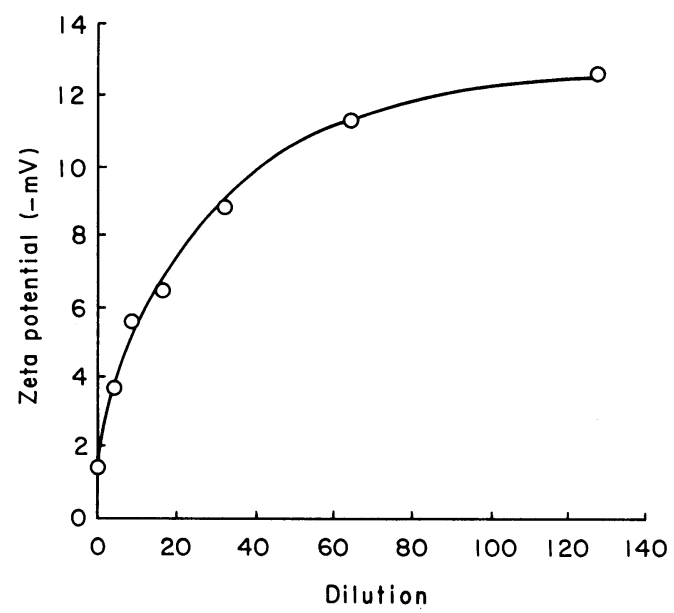

Fig. 2. The relation between the zeta potential value and the concentration of neuraminidase. Two hundred fifty $\mathrm{ml}$ of packed RBCs were incubated at $37^{\circ} \mathrm{C}$ for 20 min with varying amounts of neuraminidase under the standard assay condition.

bromelain, chymotrypsin, dispase, ficin, papain, and trypsin was $-6.05,-7.90$, $-9.04,-4.38,-8.52$, and $-7.28 \mathrm{mV}$, respectively (Table 1). Among the proteases ficin was most reducible on the zeta potential of RBCs. These results would demonstrate that the D.E.L.S. technique is useful for the determination of zeta potential of RBCs. 


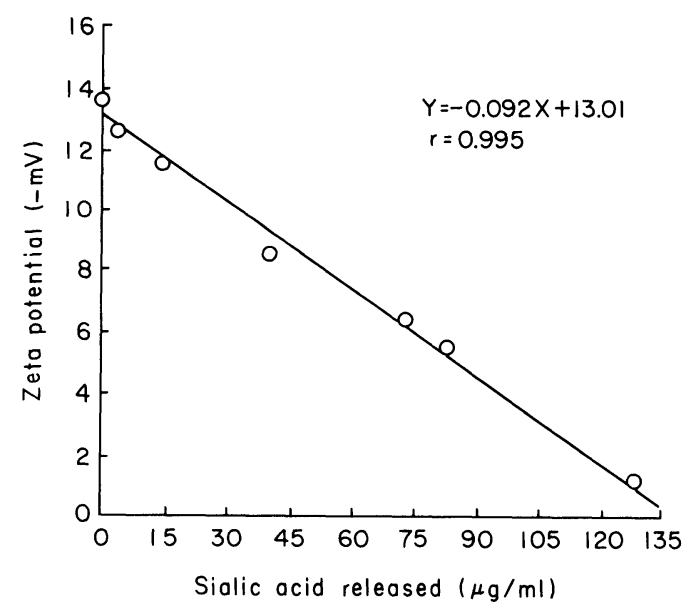

Fig. 3. The correlation between the zeta potential and the sialic acid released from RBCs by the neuraminidase treatment. The RBCs were incubated with neuraminidase at concentration of $0.4 \mathrm{U} / \mathrm{ml}$ at $37^{\circ} \mathrm{C}$ for $20 \mathrm{~min}$.

The D.E.L.S technique were applied to normal RBCs from ten individuals. The mean of zeta potential of normal RBCs from ten individuals was $-13.7 \pm 0.61$ $\mathrm{mV}$ (mean \pm s.D.) and then the spectrum of zeta potential showed only one population (Fig. 4). The amounts of released sialic acid were $125 \pm 20 \mathrm{mg} / \mathrm{ml}$ RBC (mean \pm s.D.). However the electrokinetik behavior of RBCs from a patient with Tn syndrome was clearly different from normal RBCs. The zeta potential of RBCs from a patient with Tn syndrome was $-8.67 \mathrm{mV}$, and its spectrum of zeta potential showed two distinct electrophoretic species (Fig. 5). In detail peak analysis, the peak I and peak II were $-13.32 \mathrm{mV}$ and $-4.73 \mathrm{mV}$ of zeta potential, respectively. The zeta potential of the peak II reduced at $64.5 \%$ of normal RBCs and occupied $48.8 \%$ of the whole $\mathrm{RBC}$.

TABLE 1. Effects of enzyme treatment

\begin{tabular}{lcc}
\hline \multicolumn{1}{c}{ Enzymes } & $\begin{array}{c}\text { Zeta potential } \\
(\mathrm{mV})\end{array}$ & $\begin{array}{c}\text { Reduction of zeta } \\
\text { potential }(\%)\end{array}$ \\
\hline Bromelain & -6.05 & 55.8 \\
Chymotrypsin & -7.91 & 42.3 \\
Dispase & -9.04 & 34.0 \\
Ficin & -4.38 & 68.0 \\
Neuraminidase & -1.31 & 90.4 \\
Papaine & -8.52 & 37.8 \\
Trypsin & -7.28 & 46.8 \\
Normal & -13.70 & 0 \\
\hline
\end{tabular}




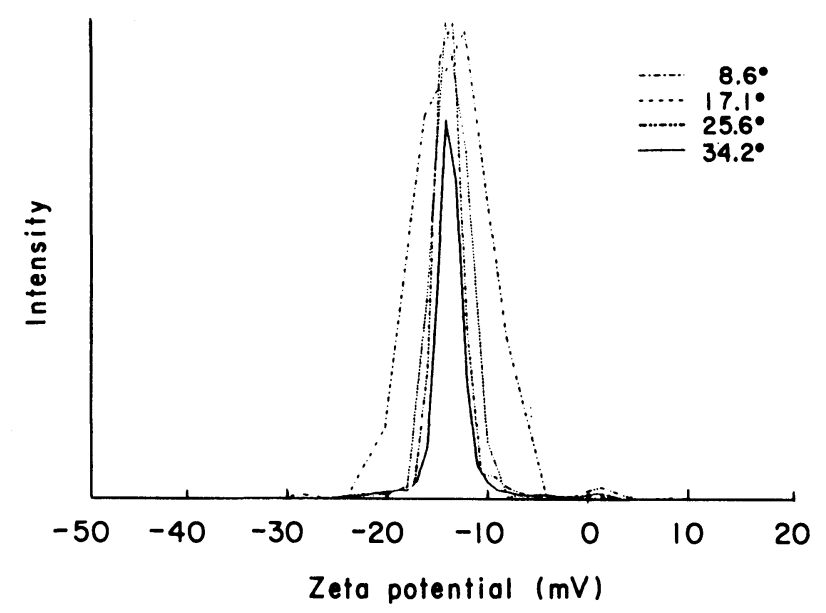

Fig. 4. The spectrum of the doppler electrophoretic light scattering of RBCs from normal donor. Relative scattered light intensity is plotted against the zeta potential.

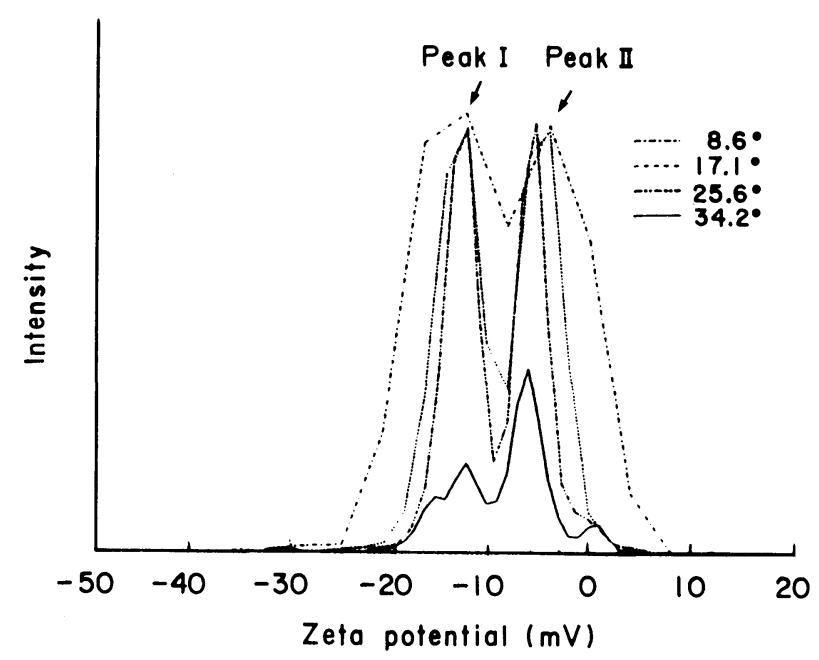

Fig. 5. The spectrum of the doppler electrophoretic light scattering of RBCs from patient with Tn syndrome. Relative scattered light intensity is plotted against the zeta potential. The zeta potentials of peak I and peak II were $-13.32 \mathrm{mV}$ and $-4.73 \mathrm{mV}$, respectively.

\section{Discussion}

Extracts of the seeds such as Doliches biflorus, Bauhinia variegara, Visia Villosa and Wistaria sinesis strongly agglutinate Tn RBCs. Previous results from our group by flow cytometric analysis showed the mixed-field polyagglutination in this patient, and its Tn RBCs were scored, of which 65.9 and $45.7 \%$ were 
labeled by polyclonal anti-Tn antibody and lectin $V$. villosa respectively, which recognizes only the Tn antigen, (Kamitani et al. 1992). In this D.E.L.S. analysis, the RBCs from Tn syndrome consisted of two distinct population; normal and abnormal. The agglutinable and non-agglutinable RBCs with Tn syndrome have been separated by their mobility, and the mobility of agglutinable RBCs decreased (Gunson et al. 1971; Myllyla et al. 1971). We therefore concluded that the zeta potential population of peak I and peak II corresponded to the tn RBCs and Tn RBCs, respectively. The zeta potential of RBCs reflects the net surface charge of the RBCs, which mainly depends on the sialic acid content of the RBCs surface (Bird et al. 1971) and the RBCs with reduced zeta potential exhibit enhanced agglutinability (Myllyla et al. 1971). The RBCs from Tn syndrome are deficient of sialic acid, depending on the incompletely synthesized oligosaccharide side chains of the glycophorins of Tn RBCs (Dahr et al. 1974), so that the zeta potential of Tn RBCs would reduce rapidly. The determinant of zeta potential of RBCs from the patient with Tn syndrome could clearly show the character of mixed-field polyagglutination and will be a useful marker of clarification of polyagglutinable RBCs.

Enzymes have been utilized extensively as probes to investigate the chemical nature of the surface of RBC membrane (Ohkuma et al. 1968; Ikemoto et al. 1975). Luner et al. have investigated effects of enzymes, which were trypsin, ficin, and neuraminidase, on RBCs membrane surface charge and showed that $95 \%-100 \%$ of this charge can be removed by the action of neuraminidase (Luner et al. 1975). It is known that neuraminidase removes only $\mathrm{N}$-acetyl neuraminic acid and does not affect the polypeptide stem bearing this charged moiety. The sialic acid removed by proteases is less than that obtained by neuraminidase. In our experiments, the percent reduction of zeta potential by neuraminidase treatment on RBCs was more than $90 \%$, and that of proteases-treament RBCs was from $38.0 \%$ to $68.0 \%$ (Table 1 ). These results corresponded to a previous report (Luner et al. 1975).

The technique of measuring cell mobility and deriving some information on the state of surface charge was much in vogue in the seventies and the electrophoretic mobility depends on $\mathrm{pH}$, ionic strength, viscosity, temperature dielectric constant of the suspending liquid (Sherbet 1978). The analytical instrument used in this experiment measures distribution of electrophoretic mobility and zeta potentials calculated from Smolucowiski equation (Pasquale et al. 1986). Recentry, the Donnan potential of cells is also reported (Kawahata et al. 1990). The zeta potential and the Donnan potential are proportional to the electrophoretic mobility, therefore, it is important that we keep constant the condition described above on cell electrophoresis.

\section{Acknowledgment}

We are extremely grateful for gifts of Tn RBCs from Dr. T. Kamesaki. We thank Mr. 
T. Oyamada for his excellent technical assistance.

\section{References}

1) Baldwin, M.L., Barrasso, C. \& Ridolfi, R.I. (1979) Tn-polyaggluyinability associated with acute myelo-monocytic leukemia. Am. J. Clin. Pathol., 72, 1024-1027.

2) Bennett, J.M., Catovsky, D., Daniel, M.T., Flandri, G., Galton, D.A.G., Gralnick, H.R. \& Sulton, C. (1982) Proposal for the classification of the myelodyspastic syndrome. Br. J. Haematol., 51, 189-199.

3) Bennett, J.M., Catovsky, D., Daniel, D., Flandri, G., Galton, D.A.G., Gralnick, H.R. \& Sulton, H. (1985) Proposed revised criteria for the classification of acute myeloid leukemia. Ann. Intern. Med., 103, 620-626.

4) Bird, G.W.G. (1977) Erythrocyte polyagglutination. In: Clinical Laboratory Science, edited by T.J. Greenwalt \& E.A. Steane, CRC Press Inc., Cleveland, O.H. 1, pp. 443-454.

5) Bird, G.W.G., Shinton, N.K. \& Wingham, J. (1971) Persistent mixed-field polyagglutination. Br. J. Hematol., 21, 443-453.

6) Bird, G.W.G., Wingham, J., Pippard, M.G., Hoult, J.G., \& Melkian, V. (1976) Erythrocyte membrane modification in mature diseases of myeloid and lymphoreticular tissues. Br. J. Hematol., 33, 289-294.

7) Cartron, J.P. \& Nurden, A.T. (1979) Galactosyltransferase and membrane glycoprotein abnormality in human platelets from Tn-syndrome donors. Nature, 282, 621623.

8) Cartron, J.P, Andreu, G., Cartron, J., Bird, G.W.G., Salmon, C. \& Gerbal, A. (1978a) Demonstration of T-transferase deficiency in Tn-polyagglutinable blood samples. Eur. J. Biochem., 92, 111-119.

9) Cartron, J.P., Cartron, J., Andreu, C., Salmon, C. \& Bird, G.W.G. (1978b) Selective deficiency of 3- $\beta$-D-galactosyltransferase (T-transferase) in Tn-polyagglutinable erythrocytes. Lancet, 1, 856-857.

10) Dahr, W., Uhlenbruck, G., Bird, G.W.G., Salmon, C. \& Gerbal, A. (1974) Cryptic alike receptor sites in human erythrocyte glycoproteins proposed nature of the $\mathrm{Tn}$ antigen. Vox Sang, 27, 29-42.

11) Eylar, E.H., Madoff, M.A., Brody, O.V. \& Oncley, J.L. (1962) The contribution of sialic acid to the surface charge of the erythrocyte. J. Biol. Chem., 237, 1992-2000.

12) Gunson, H.H., Betts, J.J. \& Nicholson, J.T. (1971) The electrophoretic mobiliy of Tn polyagglutinable erythrocytes. Vox Sang, 21, 455-461.

13) Ikemoto, S., Mukoyama, H. \& Iseki, S. (1975) Transformation of Ss Blood factors by pronase. Naturwissenschaften, 62, 189.

14) Kajii, E., Ueki, J., Ikemoto, S. \& Miura, Y. (1986) Alterations of blood group antigens in angio-immunoblastic lymphadenopathy with dysproteinemia. Am. J. Med. Sci., 292, 164-167.

15) Kamesaki, T., Akifuji, Y., Mori, M., Ueki, J., Nakamoto, S., Kajii, E. \& Ikemoto, S. (1993) A patient with Tn syndrome associated with myelodysplastc syndrome showed abnormal glycophorin B. Int. J. Haematol., 58., 113-118.

16) Kamitani, Y., Kajii, E., Suda, T. \& Ikemoto, S. (1992) Expression of the Tn antigen on erythroid cells form a patient with Tn syndrome. Jpn. J. Human Genet., 37, 271283.

17) Kawahata, S., Ohsima, H., Muramatu, N. \& Kondo, T. (1990) Charge distribution in the surface region of human erythrocytes as estimated from electromobility data. $J$. Colloid Interface Sci., 138, 182-186.

18) Luner, S.J., Sturgeon, P., Azklarek, D. \& Mcquiston, D.T. (1975) Effects of proteases and neuraminidase on RBC surface charge and agglutination. A kinetic study. Vox Sang, 28, 184. 
19) Myllyla, G., Furuhjelm, S., Nording, S., Pirkola, A., Tippett, P., Gavin, J. \& Sanger, R. (1971) Persistent mixed field polyagglutinability. Electrokinetic and serological aspects. Vox Sang, 20, 7-23.

20) Ness, P.M., Garraty, P.A., Morel, P.A. \& Perkins, H.A. (1979) Tn polyagglutination preceding acute leukemia. Blood, 54, 30-34.

21) Ohkuma, S., Ikemoto, S. \& Furuhata, T. (1968) Effect of trypsin on M and N blood-group antigens on human erythrocytes. Proc. Jpn. Acad., 44, 721-726.

22) Oyamada, T., Yoko, Y., Omi, T., Kajii, T., Kamesaki, T., Ueki, J. \& Ikemoto, S. (1991) A case of Tn-polyagglutination associated with refractory anemia with excess of blasts (RAEB). Jpn. J. Comparat. Clin. Haematol., 1, 16-25.

23) Pasquale, L., Winiski, A., OLiva, C., Vaio, G. \& Mclaughlin, S. (1986) An experimental Test of New theoretical Models for the electrolinetic properties of biological membranes. The effect of UO2 and Tetracaine on the electrophoretic mobility of bilayer membranes and human erythrocytes. J. Gen. Physiol., 88, 697-718.

24) Roelcke, D. (1973) Specificity of IgA cold agglutinins: Anti-Prl. Eur. J. Immunol., 3, 206-212.

25) Sherbet, G.V. (1978) The Biophizical Characterization of the Cell Surface. Academic Press, London.

26) Vainchenker, W., Vinci, G., Testa, U., Henri, A., Tabilo, A., Fache, M.P., Rochant, H. \& Cartron, J.P, (1985) Presence of the Tn antigens on hematopoietic progenitors from patints with the Tn syndrome. J. Clin. Invest., 75, 541-546.

27) Warren, L. (1959) The thiobarbituratic acid assay of sialic acids. J. Biol. Chem., 234, 1971-1975. 